\title{
The Challenges of Living with and Caring for a Child or Children Affected by Neuronal Ceroid Lipofuscinosis Type 2 Disease: In-Depth Family Surveys in the United Kingdom and Germany
}

Journal of Inborn Errors of Metabolism \& Screening 2020, Volume 8: e20190013 DOI: 10.1590/2326-4594-JIEMS-2019-0013

\author{
Angela Schulz', Mohit Jain ${ }^{2}$, Thomas Butt ${ }^{3}$ (D), Rachel Ballinger ${ }^{4}$, \\ Lina Eliasson ${ }^{4}$, Jake Macey ${ }^{4}$, Tessa Peasgood ${ }^{5}$, Andrew Olaye ${ }^{2}$, \\ Irini-Alexia Terzakis-Snyder ${ }^{6}$, Iris Dyck ${ }^{7}$ and Andrea West ${ }^{8}$
}

\begin{abstract}
Limited research has investigated the challenges faced by families caring for children with neuronal ceroid lipofuscinosis type 2 (CLN2) disease. Face-to-face, mixed-method, in-depth surveys were conducted with 19 families (23 children) in the UK ( $\mathrm{n}=9)$ and Germany $(n=10)$ to assess the impact of caring for children with CLN2 disease, using national wellbeing and quality of life (QoL) measures. Primary $(n=19)$ and secondary $(n=10)$ caregivers, adult siblings $(n=2)$, and child siblings $(n=2)$ were included. Caregivers reported reduced health-related QoL compared with age and gender-matched controls (mean utility scores 0.08 and 0.11 lower in Germany and the UK, respectively). Hours of caregiving were significantly higher relative to that provided to a child of normal health, with stress, back pain, and reductions in sleep being recorded. Lower life satisfaction and happiness with partners were also reported, along with significant financial burden. Those caring for children in the late stage of disease were more greatly impacted than those with children in the rapidly progressive stage, or who were bereaved. The results of this study make clear the importance of emotional and practical support for caregivers and siblings coping with CLN2 disease.
\end{abstract}

\section{Keywords:}

Rare disease, Family, Disease burden, CLN2 disease, Batten disease.

\section{Background}

Neuronal ceroid lipofuscinosis type 2 (CLN2) disease is part of a group of rare, progressive, degenerative, neurometabolic disorders called neuronal ceroid lipofuscinoses (NCLs; also known as Batten disease) [1-3]. This rare, autosomal recessive disorder is caused by pathologic variants (mutations) in the TPP1 gene (also known as the CLN2 gene) which lead to deficiency of an enzyme called tripeptidyl peptidase 1 (TPP1). The deficiency of TPP1 results in abnormal levels of storage materials in neurons and other cells, and ultimately neuronal loss in the central nervous system [4-5].

Onset of CLN2 disease generally begins when the child is aged 2-4 years, followed by a rapid decline in motor and language abilities [6]. The first symptoms frequently reported are seizures; however, a significant delay in language development often precedes the first seizure [7]. Affected children have usually lost

\footnotetext{
${ }^{1}$ University Medical Center Hamburg-Eppendorf, Children's Hospital, Hamburg, Germany.

${ }^{2}$ BioMarin Europe Ltd., London, United Kingdom.

${ }^{3}$ University College London, UCL Institute of Ophthalmology, London, United Kingdom.

${ }^{4}$ ICON Plc., Abingdon, United Kingdom.

${ }^{5}$ University of Sheffield, School of Health and Related Research, Sheffield, United Kingdom.

${ }^{6}$ Terzakis Consulting, Erlangen, Germany.

${ }^{7} \mathrm{NCL}-$ Gruppe Deutschland e.V., Berlin, Germany.

${ }^{8}$ Batten Disease Family Association, Farnborough, United Kingdom.
}

Received November 07, 2019, and in revised form March 20, 2020.

Accepted for publication April 06, 2020.

\section{Corresponding Author:}

Thomas Butt, UCL Institute of Ophthalmology, University College London, London, United Kingdom.

Email: thomas.butt@ucl.ac.uk 
their language ability, are non-ambulant and are suffering from a severe movement disorder with myoclonus and dystonia by the age of six years. Life expectancy of those with CLN2 disease varies from between six years and the early teenage years.

Due to the rarity of the disease, epidemiological data on CLN2 disease is limited. Based on the few available reports, the worldwide prevalence is estimated as 0.75 per million population with a 0.5 incidence rate per 100,000 live births [8-10]. A study in the UK found that the prevalence of CLN2 disease was 0.31 per million population with a birth incidence of 0.78 per 100,000 live births [8]. The Batten Disease Family Association (BDFA) have estimated that between 30 and 50 children have CLN2 disease in the UK, with five to six children being diagnosed each year [11]. In Italy, 183 patients with NCLs were recruited over a 13-year period, and when 124 of these patients were tested for known NCL genes, CLN2 disease was diagnosed in $24 \%$ of cases [12].

Curative treatment for CLN2 disease does not currently exist. Replacement of the deficient enzyme (using cerliponase alfa; Brineura ${ }^{\circledR}$ ), has been found to slow decline in motor and language function in patients with CLN2 disease [13] and, following completion of the study reported here, this therapy was approved for use by the Food and Drug Administration (FDA) [14] and European Medicines Agency (EMA) [15]. Further therapies, including gene therapy and various pharmacological agents, are in pre-clinical and clinical development [16-19].

Life-limiting conditions such as CLN2 disease, cystic fibrosis, Duchenne muscular dystrophy, spina bifida or cerebral palsy have a multidimensional impact, influencing physical, emotional, financial, and spiritual dimensions of the life of the families involved in caring for children with the disease [20-27]. Families caring for those with life-threatening illnesses can experience changes in work patterns, income, and domestic duties [27]. Parents and siblings may require specialist health knowledge, caregiving skills, and resources beyond those normally required when caring for a healthy child [22, 28-30]. Caregivers may experience negative feelings (grief, upset, anger, and frustration) and may feel frustrated with the professional support they receive to deal with mental health issues [31].

Limited research has been undertaken to investigate the specific challenges faced by families caring for children affected by CLN2 disease. A UK survey of families with children with life-limiting conditions, including nine families with Batten disease, found that symptoms that led to parental exhaustion or were difficult to control, were the most challenging to manage for caregivers [21]. In studies conducted by UK- and US-based NCL patient advocacy organizations, parents have reported diagnostic delays, with many parents feeling frustrated with the support they have received from healthcare professionals (HCPs), and significant financial and social impacts as they care for their child [32]. However, none of these studies have specifically looked at CLN2 disease or quantified the burden of disease affecting the caregivers in relation to the normal population.

\section{Aims}

The aim of this study was to explore the challenges that families face and their health-related quality of life (HRQoL) when living with and caring for a child or children affected by CLN2 disease.

\section{Methods}

\section{Overall Study Design}

This study, which was conducted between January 2015 and July 2016, comprised a development stage involving a targeted literature review and focus group discussions (conducted in the UK), followed by mixed-method, in-depth family surveys (conducted in the UK and Germany). The surveys comprised interviewer-led, open, qualitative and multiple choice questions, and self-completed pre-existing quality of life (QoL) measures [33-40] for quantitative analysis, including comparisons to population norms where available.

\section{Development Stage}

A targeted literature review was conducted in January 2015 to assess the current understanding of caregiver and sibling burden for those with a child with CLN2 disease or other rare, genetic, life-limiting condition. The results were used to inform the study protocols and survey development. Focus groups explored the challenges families face in living with and caring for a child or children with CLN2 disease, and the impact of the loss of a child or children with CLN2 disease. The focus group consisted of eight females and three males from six families, corresponding to four children who were still alive, and four deceased children. Six participants reviewed the family background form and draft caregiver and sibling surveys. One sibling aged 12 years provided feedback on the sibling survey in a one-on-one interview. The outcomes of the focus group discussions were used to inform the study protocol and finalize the survey questions. These included questions from national wellbeing surveys, to assess caregiver burden by comparison to age-matched controls from the general population (described further below). These were also reviewed by clinical and patient group experts. The surveys were developed in English and the final version was translated into German.

\section{Surveys}

In the adult caregiver survey, HRQoL was assessed using EuroQoL five-dimension, 5-level questionnaire (EQ-5D-5L) measures and by asking five domain questions and visual analog scale questions [35]; Quality of Life During Serious Illness Family Caregivers (QOLLTI-F), 16 items [37]; Pediatric Quality of Life Inventory - Family Impact Module (PedsQL-FIM), 36 
items in eight domains [38]; happiness as a single item from the European Social Survey [41]; and a list of 24 study-specific physcial and emotional impact items. Impact on sleep and number of hours providing care were assessed using single items from the Understanding Society survey [33] and a multiple choice question about feeding and nutrition.

Support given to the child with CLN2 disease was assessed using four study-specific multiple choice questions (ranging from 1-14 items). Support for caregivers was assessed using one multiple choice study-specific question with 12 items. Happiness with partners was assessed using a single item from the Understanding Society survey [33]. Financial management was also assessed using a single item from the Understanding Society survey [33] and a study-specific multiple choice question about funding of home purchases for adaptations. Work productivity was assessed by the six-item Work Productivity and Activity Impairment measure [34], and two study-specific questions (one a list of 14 work-related impact items). Throughout the survey, qualitative questions were included and results provide insight and depth to the quantitative measures and items used. Many of these measures and items were also used for the adult sibling survey but there was more difference to the child sibling survey. The survey contents are outlined in Table 1, and the various QoL measures including those from national wellbeing surveys are described in Table 2. In summary, the survey assessed the following: HRQoL, sleep, hours spent caregiving, support to the child and caregiver, happiness with partner, financial management, and work and activity impairment. This was based on a combination of study-specific questions and standardized patient-reported outcomes (PRO) tools, as well as items taken from national wellbeing measures, to facilitate comparison with the general population. A copy of the three surveys can be found in the Supplementary Material files 1-3.

\section{Survey: demographic assessment}

Demographic questions were developed for self-completion separately from conduct of the survey. One caregiver per family completed questions concerning the family's demographics and the demographics of the child(ren) with CLN2 disease. For current caregivers, a study-specific adaptation of the Hamburg late-infantile (LI)NCL Scale was used to assess the disease stage of the affected child. The Hamburg Scale is a clinician-reported measure used to assess disease progression by scoring motor function, visual function, language function, and frequency of Grand Mal seizures of the child. Possible scores on each domain are between 0 and 3 leading to a maximum score of 12, where lower scores overall, generally reflect later disease stage [43]. However, lower scores on the vision and seizure domains are not equivalent to disease progression on the motor and language domains. These questions were adapted for caregiver completion in several ways to make them more layperson friendly, first, by presenting each of the four domains as questions instead of the table format (e.g. 'Is your child with CLN2 able to walk normally' which replaced 'Motor'). Second, parents were instructed to 'tick one' box which replaced the 0-3 scale on the table. Third, response options were slightly rephrased to better align to the question format in the Motor domain: following the question 'Is your child with CLN2 able to walk normally' two options were prefixed with 'yes' ('yes' and 'yes, with frequent falls or with obvious clumsiness') which replaced table format, 'Walks normally' and 'Frequent falls, obvious clumsiness'. Fourth, a few linking words were added in two response options (e.g., 'Recognizes and grabs at desirable objects' replaced 'Recognizes desirable object, grabs at it'). Fifth, other types of minor modification were made to make them more layperson friendly ('No visual function' replaced 'No reaction to visual stimuli'), to add greater specificity ('Reacts to light only' replaced 'Reacts to light'; 'Never' replaced 'No seizures in 3 months'), and to replace mathematical symbols ('More than' replaced ' $>$ '). These caregiver ratings were to be supplemented with expert clinical review of video recordings of the child using the Hamburg Scale. Questions used in a previous study [44] relating to the amount of assistance the child required for various activities (e.g., eating, bathing, or toileting) were also completed.

The study protocol and materials were reviewed and approved by an Institutional Review Board (Salus IRB, protocol numbers 0439-0037 and 0439-0037-Phase 2) and by a local ethics board in Germany (Ethikkommission der Ärztekammer Hamburg, study reference PV5057).

\section{Eligibility, recruitment, and consent}

Eligible participants were family members (adult caregivers, adult siblings, and child siblings) who currently, or had previously, cared for a child or children with CLN2 disease and whose child or children had not taken part in any previous or current clinical trial for CLN2 disease. Recruitment into the study was assisted by the patient advocacy organizations and clinical centres (BDFA [UK] and NCL-Gruppe Deutschland e.V. [Germany]) as well as the NCL specialty clinic at the Children's Hospital, University Medical Center Hamburg-Eppendorf (Germany). Individuals voluntarily agreed to take part and gave their written informed consent at the commencement of the study. Child participants provided their written assent and a parent provided their proxy consent.

\section{Administration}

Researchers conducted the survey in person with one family member at a time, in the participant's home or other agreed venue. The surveys were audio recorded and transcribed verbatim for qualitative analysis. German audio data were transcribed directly into English. Quantitative data were entered onto a study-specific database in Excel. Quality control checks were applied to all study data prior to analysis. 
Table 1. Outline of survey content.

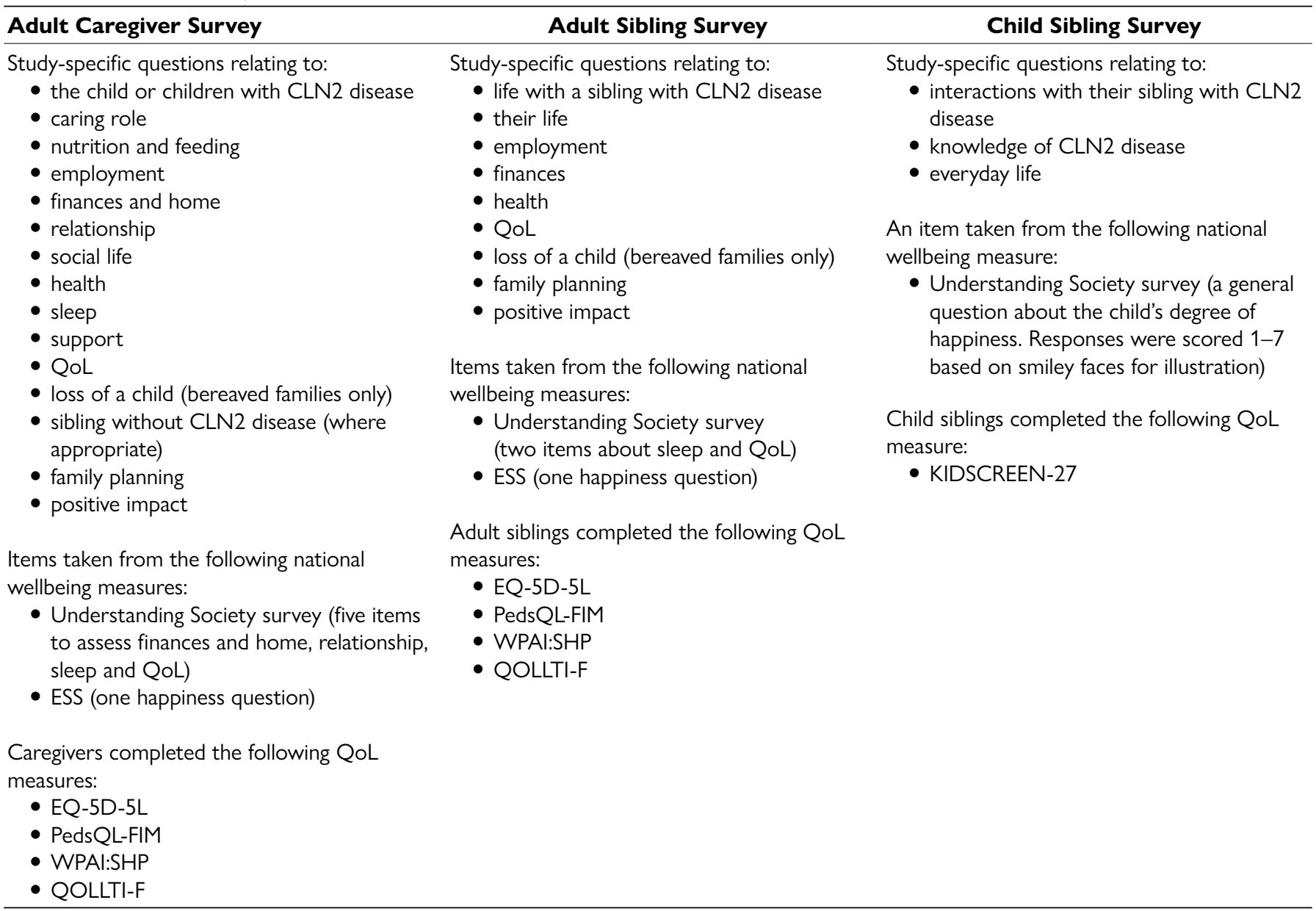

CLN2, ceroid lipofuscinosis neuronal type 2; EQ-5D-5L, EuroQoL five-dimension, five-level questionnaire; ESS, European Social Survey; KIDSCREEN-27, Child and Adolescent Version; PedsQL-FIM, Pediatric Quality of Life Inventory - Family Impact Module (v2); QOL, quality of life; QOLLTI-F, Quality of Life During Serious Illness - Family Caregivers; WPAI:SHP, Work Productivity and Activity Impairment Questionnaire: Specific Health Problem (v2).

Table 2. Descriptions of national wellbeing and quality of life measures used in the survey

\begin{tabular}{|c|c|}
\hline Measure & Description \\
\hline ESS [41] & $\begin{array}{l}\text { A survey that assesses the attitudes, beliefs, and behavior patterns of the various populations in Europe. One overall } \\
\text { happiness question from ESS included in the study survey (adults only). }\end{array}$ \\
\hline Understanding Society survey [33] & $\begin{array}{l}\text { A survey used in the UK Household Longitudinal Study (UKHLS). Five items assessing finances, home, relationship, } \\
\text { sleep, and QoL were included in this study (adult caregivers only). Two items (sleep and QoL) were used with adult } \\
\text { siblings. One child-specific item (happiness) was used for child siblings. }\end{array}$ \\
\hline WPAI:SHP [34] & $\begin{array}{l}\text { Six-item measure to assess the number of hours worked, productivity at work, and the ability to do day-to-day } \\
\text { activities. Four scores were derived: percentage of absenteeism, percentage of presenteeism (reduced productivity } \\
\text { while at work), an overall work impairment score that combines absenteeism and presenteeism, and percentage of } \\
\text { impairment in activities performed outside of work. Greater scores indicate greater impairment. }\end{array}$ \\
\hline EQ-5D-5L health questionnaire [35] & $\begin{array}{l}\text { A five-dimension measure to assess the level of mobility, self-care, usual activities, pain/discomfort, and anxiety and } \\
\text { depression on the day of the survey. The five-level version was used. }\end{array}$ \\
\hline EQ-5D utility score [35] & $\begin{array}{l}\text { Combining the dimensions can generate an overall utility score. This is based on a social tariff which applies } \\
\text { population preferences to the EQ-5D state [31]. For Germany, a tariff representing social values or preference } \\
\text { weights was available for the three level EQ-5D only. } \\
\text { For the UK, a social tariff was available for both versions, but the new EQ-5D-5L social tariff had not yet been } \\
\text { endorsed. Therefore, a mapping algorithm was used to predict (cross-walk) the EQ-5D-3L score from the EQ-5D- } \\
5 \mathrm{~L} \text { version. } \\
\text { Anchored at } 0 \text { (equivalent to dead) to } 1 \text { (full health). }\end{array}$ \\
\hline
\end{tabular}


Table 2. Cont.

\begin{tabular}{|c|c|}
\hline Measure & Description \\
\hline EQ-5D VAS [35] & $\begin{array}{l}\text { A visual analog scale used along with the EQ-5D to assess overall health of the adult participants, where } 0=\text { "worst } \\
\text { possible life" and } 100=\text { "best possible life". }\end{array}$ \\
\hline QOLLTI-F [37] & $\begin{array}{l}\text { A 16-item measure to assess the state of caregiver, patient well-being, quality of care, outlook, environment, } \\
\text { finances, and relationships. Used a } 0 \text { to } 10 \text { Likert scale, with higher values indicating a higher quality of life. }\end{array}$ \\
\hline PedsQL:FIM [38] & $\begin{array}{l}\text { An eight-domain measure to assess physical functioning, emotional functioning, social functioning, cognitive } \\
\text { functioning, communication, worry, difficulty for the family in relation to daily activities, and family relationships over } \\
\text { the past month. } \\
\text { A parent quality-of-life sub-scale measured parent self-reported physical, emotional, social, and cognitive functioning. } \\
\text { A modified parent quality-of-life sub-scale also including communication. Score from } 0 \text { to } 100 \text {, with higher scores } \\
\text { indicating better quality of life. }\end{array}$ \\
\hline KIDSCREEN-27 $[39,40]$ & $\begin{array}{l}\text { Twenty-seven self-reported items which assess health and physical activities, mood and feelings, family and free time, } \\
\text { friends and school, and learning. Validated for individuals aged } 8-18 \text { years. } \\
\text { The KIDSCREEN-27 was mapped onto CHU-9D. A quality-adjusted life-year (QALY) score was then generated, } \\
\text { where } 0 \text { corresponded to dead and } 1 \text { corresponded to full health-related quality of life. }\end{array}$ \\
\hline CHU9D [42] & $\begin{array}{l}\text { A nine-dimension measure which includes worried, sad, pain, tired, annoyed, school work/homework, sleep, daily } \\
\text { routine and ability to join in activities. Each dimension has five levels. Combining the dimensions generates an overall } \\
\text { utility score. }\end{array}$ \\
\hline
\end{tabular}

CHU9D, Child Health Utilities Nine Dimensions questionnaire; EQ-5D, EuroQoL five-dimension questionnaire; EQ-5D VAS, EuroQoL visual analog scale; EQ-5D-5L, EuroQoL five-dimension, five-level questionnaire; ESS, European Social Survey; KIDSCREEN-27, Child and Adolescent Version; PedsQL:FIM, Pediatric Quality of Life Inventory - Family Impact Module (v2); QOLLTI-F, Quality of Life During Serious IIIness - Family Caregivers; UKHLS, UK Household Longitudinal Study; WPAI:SHP, Work Productivity and Activity Impairment Questionnaire: Specific Health Problem (v2).

\section{Analysis}

Demographic data were summarized using descriptive statistics. Quantitative data from completion of the national wellbeing and QoL measures were analyzed using Stata software. Adult siblings $(n=2)$ were added to the caregiver dataset for analysis of HRQoL and work productivity (as reported below). For the EQ-5D-5L, two utility scores were generated: one from the new EQ-5D-5L tariff for the UK, and one based on the cross-walk mapping onto the EQ-5D-3L using the UK cross-walk and the German cross-walk for the two countries, respectively. Outcome measures between the adult caregivers and a comparison group from the Understanding Society cohort general population and a cohort of parents caring for an unwell child (where available) were analyzed using the two independent samples t-test. A 95\% confidence interval for estimated mean differences between the groups was calculated and $P$-value reported. The comparison group from the general population was matched according to age and gender, with some comparisons between parents of children that were the same age. Subgroup analysis was conducted by child's disease stage (informed by the caregivercompleted Hamburg Scale questions) or bereavement status, and by country. The total scores of the Hamburg Scale were classed as early stage (6/12 total score, with a minimum combined score of $\geq 5$ on motor and language scores), rapidly progressive stage (3-5/12 total score), or late stage (0-2/12 total score). Survey transcripts were uploaded into qualitative software (MAXQDA version 11) and codebooks developed to ensure consistency in coding of qualitative data. Coded qualitative data were analyzed thematically and all analyses were reviewed by a statistical expert.

\section{Results}

\section{Participant and Family Characteristics}

In total, 25 families were identified by the BDFA and NCLGruppe who met the eligibility criteria. Two of these families decided not to take part for personal reasons and four families did not reply to the study invitation. Nineteen different families in the $\mathrm{UK}(\mathrm{n}=9)$ and Germany $(\mathrm{n}=10)$ took part in the surveys that were conducted between September 2015 and February 2016 (Table 3). The sample consisted of 19 primary caregivers ( 15 females, 4 males), 10 secondary caregivers ( 3 females, 7 males), 2 adult siblings (both female) and 2 child siblings (both female), and corresponded to 12 children with CLN2 disease who were still alive, and 11 deceased children. Of the 19 participating families, the majority $(10 / 19,53 \%)$ comprised two study participants; seven families comprised one study participant, and two families had three participants. Ten families (53\%) were caring for one child with CLN2 disease; five families (26\%) had lost one child with CLN2 disease; two families (11\%) had lost one child with CLN2 disease and were caring for a second child with CLN2 disease; and two families (11\%) had lost two children with CLN2 disease.

While patients could be classified into three stages (early, rapidly progressive, late) in general, no patients in this sample fell into the early stage (total score $\geq 10$ with a minimum combined score of 5 on motor and language domains). Therefore, the 12 families (63\%) currently caring for a child or children with CLN2 disease were classified into either rapidly progressive stage $(n=4$, total score $\geq 3)$ or late stage $(n=8$, total score $0-2$ with 0 on the motor or language domains) on the basis of the caregiver- 
completed Hamburg Scale. The other seven families (37\%) were classified as bereaved. In the UK, families were spread across the three groups. In Germany, families were mainly caring for children who were in the late stage, or were bereaved.

The mean staging score of the 12 living children (Table 4) indicates that they were generally in the later stages of CLN2 disease and severely impacted by the disorder.

\section{Health-related Quality Of Life}

EQ-5D utility scores indicated that UK and German caregivers, including adult siblings, experienced a reduced HRQoL compared with age and gender-matched controls. German caregivers had mean EQ-5D utility scores 0.08 below their age/gender population norm $(p<0.05)$, and UK caregivers

Table 3. Demographic details of family members

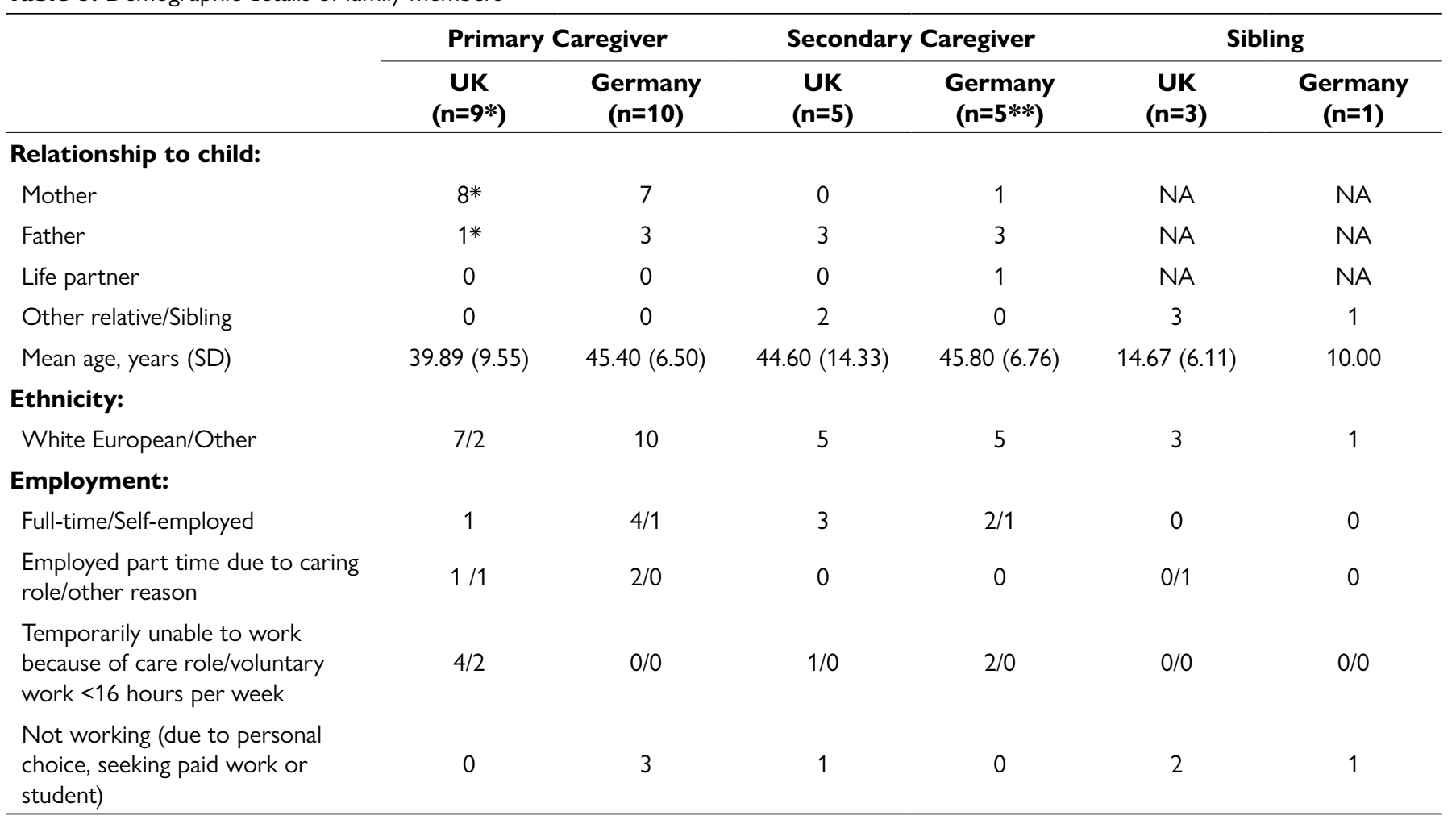

The UK sample comprised 9 families in the UK, with a total of 17 individuals. The German sample comprised 10 families, with a total of 16 individuals. *Both the mother and father in one family considered themselves a primary caregiver. ** Caregiver primary or secondary status was missing from one participant. For descriptive purposes here they were classified as a secondary caregiver as their spouse had indicated themselves as a primary caregiver. NA, not applicable; SD, standard deviation; UK, United Kingdom.

Table 4. Demographic details of the children with CLN2 disease

\begin{tabular}{|c|c|c|c|c|}
\hline & \multicolumn{2}{|c|}{ Children Alive } & \multicolumn{2}{|c|}{ Children Deceased } \\
\hline & $\begin{array}{c}\text { UK } \\
(n=6)\end{array}$ & $\begin{array}{c}\text { Germany } \\
(n=6)\end{array}$ & $\begin{array}{c}\text { UK } \\
(n=6)\end{array}$ & $\begin{array}{c}\text { Germany } \\
(n=5)\end{array}$ \\
\hline $\begin{array}{l}\text { Mean current age/age at death (SD), } \\
\text { years [range in years] }\end{array}$ & $\begin{array}{c}5.67(1.75) \\
{[4-9]}\end{array}$ & $\begin{array}{c}13(7.35) \\
{[6-26]}\end{array}$ & $\begin{array}{l}9(2.19) \\
{[6-12]}\end{array}$ & $\begin{array}{l}11.15(2.41) \\
\quad[9-15]\end{array}$ \\
\hline $\begin{array}{l}\text { Mean age at diagnosis (SD), years } \\
\text { [range in years] }\end{array}$ & $\begin{array}{l}3.17(0.75) \\
\quad[2-4]\end{array}$ & $\begin{array}{l}6.29(5.38) \\
{[2-16]}\end{array}$ & $\begin{array}{c}4(1.55) \\
{[1-5]}\end{array}$ & $\begin{array}{l}2.55(1.66) \\
{[0 *-4]}\end{array}$ \\
\hline Male/female, no. & $3 / 3$ & $3 / 3$ & $3 / 3$ & $0 / 5$ \\
\hline $\begin{array}{l}\text { Mean of the Hamburg LINCL Scale } \\
\text { score (SD) }\end{array}$ & $\begin{array}{l}0.75(1.07) \\
\text { range } 0-7\end{array}$ & $\begin{array}{l}0.25(0.53) \\
\text { range } 0-3\end{array}$ & NA & NA \\
\hline
\end{tabular}

*Caregiver indicated child was diagnosed with CLN2 disease aged 2 months. LINCL, late-infantile neuronal ceroid lipofuscinosis; NA, not applicable; SD, standard deviation; UK, United Kingdom. 
had an EQ-5D utility score 0.11 lower $(p<0.01)$ (Figure 1). The majority of caregivers reported at least slight problems with pain/ discomfort $(\mathrm{n}=21,68 \%)$ and/or anxiety/depression $(\mathrm{n}=22,71 \%)$; approximately one third of caregivers reported at least slight problems with usual activities. No problems were reported by most with self-care (Table 5).

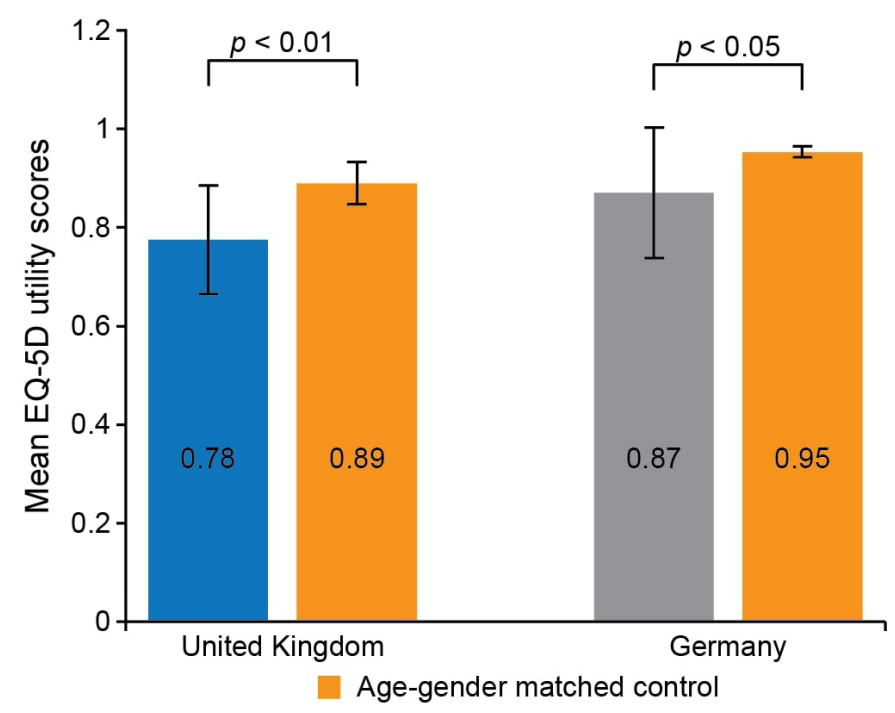

Figure 1. $H R Q \circ L$ measured using the EQ-5D-5L questionnaire cross-walk into EQ-5D-3L in caregivers in the United Kingdom and Germany compared with age/gender-matched controls [31]. A score of 1 indicates "perfect health", a score of 0 indicates "death" (includes adult siblings). EQ-5D-3L, EuroQoL five-dimension, threelevel questionnaire; EQ-5D-5L, EuroQoL five-dimension, five-level questionnaire; HRQoL, health related quality of life.

The QoL of caregivers was lower in the UK than Germany by QOLLTI-F and PedsQL-FIM results (Table 6).

Caring for a child with CLN2 disease had an impact on a caregiver's physical wellbeing, with many participants reporting a significant impact on their physical health in relation to stress (90\%), lack of sleep (93\%) and back pain (66\%) (Figure 2A). Across both UK and German caregivers, the majority placed the needs of their child before their own (83\%), indicated that they felt burdened (66\%) and experienced anxiety (52\%); yet many also experienced a more positive outlook (41\%; especially in Germany) (Figure 2B). Two caregivers reported that they felt burdened and anxious, but were keen to specify that this was because of the situation rather than because of their affected child. Caregivers reported "having to get on with it" (UK3) and although they felt very sad and upset at times, they had learned to accept the situation as it was and deal with it.

\section{Impact on Sleep Patterns}

When compared with normative data from parents who cared for a sick or disabled child, parents with a child with CLN2 disease had significantly fewer hours sleep per night (mean 5.4 vs. 6.2 hours; $p<0.01$; Table 7 and Figure $3 \mathrm{~A}$ ). Compared with parents with a child of the same age, caregivers of a child with CLN2 disease reported 1.3 fewer hours sleeping per night $(p<0.01$, Table 7$)$.

Those caring for a child in the late stage of disease had slightly less sleep than those caring for a child in the rapidly progressive stage ( 4.8 vs. 6.0 hours, Figure 3A). Caregivers described how they "sleep with one eye open" (C24) and that they "never really [...] switch off to it" (C20). Often there was variation every night in how easily children went to sleep, as well as frequency and nature of their night-time waking (e.g. seizures, screaming).

\section{Caregiving Hours}

Compared with parents with a child of the same age, caregivers of a child with CLN2 disease (both UK and German combined) reported significantly more caring hours per week (mean 73.4 hours; $p<0.01$, Table 7 ). Primary caregivers of a living child reported a substantially higher carer load than secondary caregivers (95.5 vs. 49.8 hours). The hours caring for a child with late-stage disease were significantly more than the hours spent caring for a child in the rapidly progressive stage ( 99.0 vs. 42.6 hours, $p<0.05$; Figure $3 \mathrm{~B}$ ). Mothers typically reported a higher carer load than fathers ( 85 vs. 68 hours), which reflected that generally they were the primary caregiver. Difficulties were also reported with feeding and nutrition (see Table 8 and Supplementary Material file 4). Across the disease trajectory, higher caregiving hours were driven by frequent hospital appointments and a larger number of medications to administer to the affected child; late-stage disease was characterized by recurrent hospital admissions and physical support of the child as motor function deteriorated.

\section{Support Given to the Child with CLN2 Disease}

Most participants felt their child or children with CLN2 disease were able to see all the HCPs they needed; however, there was still about a quarter overall that did not feel this was the case, and this was slightly higher in Germany than the UK.

Several caregivers reported how the quality of support and care they received from HCPs (e.g. nurses, pediatricians and other specialists, and school support staff) differed between professional groups (see Supplementary Material file 4) and individuals, and that this was linked to HCPs' knowledge of CLN2 disease. In addition to lack of knowledge, negative experiences with physicians were related to the physician's inability to listen empathically, dissatisfaction with their communication style and diligence, as well as the perceived low level of genuine interest taken in the child with CLN2 disease and their family.

Generally, caregivers in the UK were satisfied with the current level of care and support their affected child received from the various general service areas (disability benefits, education services, medical care and social services) (Figure 4). One caregiver felt lucky with the level of support and how the area they lived in was "very well set up for people with disabilities" 
Table 5. EQ-5D analysis by dimension with UK and Germany combined (including adult siblings)

\begin{tabular}{|c|c|c|c|c|c|}
\hline & & $\begin{array}{c}\text { Total } \\
(n=31)\end{array}$ & $\begin{array}{c}\text { Rapidly } \\
\text { progressive stage } \\
(n=6)\end{array}$ & $\begin{array}{l}\text { Late stage } \\
\qquad(n=15)\end{array}$ & $\begin{array}{c}\text { Deceased } \\
(n=10)\end{array}$ \\
\hline \multirow{3}{*}{ Mobility } & No problems & $24(77 \%)$ & $4(67 \%)$ & $11(73 \%)$ & $9(90 \%)$ \\
\hline & Slight problems & $5(16 \%)$ & $1(17 \%)$ & $3(20 \%)$ & $1(10 \%)$ \\
\hline & Moderate problems & $2(6 \%)$ & $1(17 \%)$ & $1(7 \%)$ & $0(0 \%)$ \\
\hline \multirow[t]{2}{*}{ Self-care } & No problems & $31(100 \%)$ & $6(100 \%)$ & 15 (100\%) & $10(100 \%)$ \\
\hline & No problems & $20(65 \%)$ & $3(50 \%)$ & $8(53 \%)$ & $9(90 \%)$ \\
\hline \multirow{3}{*}{ Activities } & Slight problems & $8(26 \%)$ & $2(33 \%)$ & $5(33 \%)$ & $1(10 \%)$ \\
\hline & Moderate problems & $2(6 \%)$ & $1(17 \%)$ & $1(7 \%)$ & $0(0 \%)$ \\
\hline & Severe Problems & $1(3 \%)$ & $0(0 \%)$ & $1(7 \%)$ & $0(0 \%)$ \\
\hline \multirow{4}{*}{ Pain } & No problems & $10(32 \%)$ & $1(17 \%)$ & $4(27 \%)$ & $5(50 \%)$ \\
\hline & Slight problems & $14(45 \%)$ & $4(67 \%)$ & $6(40 \%)$ & $4(40 \%)$ \\
\hline & Moderate problems & $6(19 \%)$ & $1(17 \%)$ & $4(27 \%)$ & $1(10 \%)$ \\
\hline & Severe Problems & $1(3 \%)$ & $0(0 \%)$ & $1(7 \%)$ & $0(0 \%)$ \\
\hline \multirow{4}{*}{ Anxiety } & No problems & $9(29 \%)$ & $1(17 \%)$ & $4(27 \%)$ & $4(40 \%)$ \\
\hline & Slight problems & $13(42 \%)$ & $3(50 \%)$ & $5(33 \%)$ & $5(50 \%)$ \\
\hline & Moderate problems & $7(23 \%)$ & $1(17 \%)$ & $5(33 \%)$ & $1(10 \%)$ \\
\hline & Severe Problems & $2(6 \%)$ & $1(17 \%)$ & $1(7 \%)$ & $0(0 \%)$ \\
\hline
\end{tabular}

EQ-5D, EuroQoL five-dimension questionnaire.

Table 6. Impact of disease stage and country on quality of life measures (excludes adult siblings)

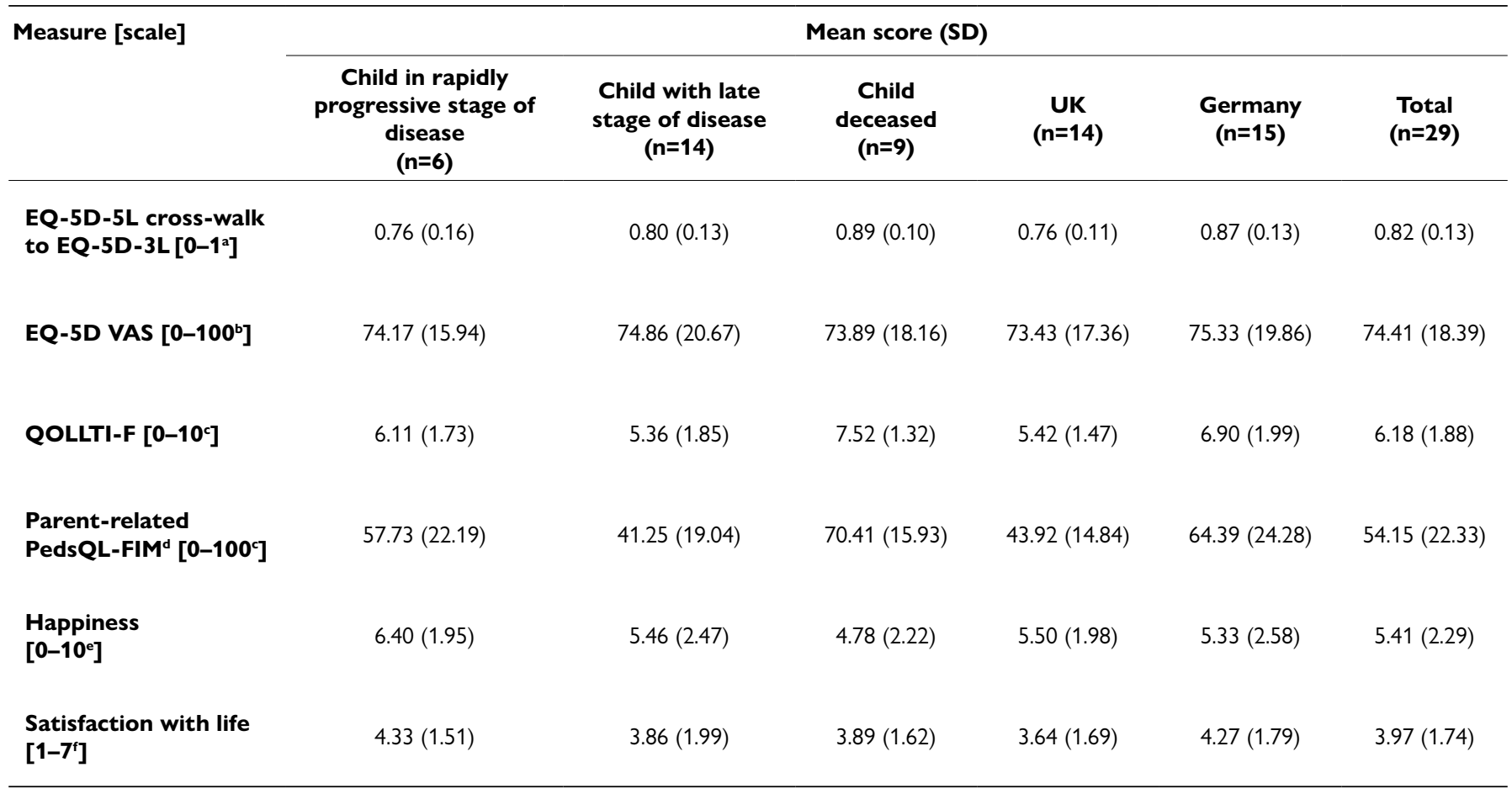

aUtility score where 1 indicates "perfect health" and 0 indicates "death"; ${ }^{\circ} 0$ indicates "worst possible life" and 100 indicates "best possible life"; "Higher values indicate higher quality of life; ${ }^{\mathrm{d}} \mathrm{A}$ modified parent self-reported measure that used 5 subscales; ${ }^{\circ} 0$ indicates extremely unhappy and 10 indicates extremely happy; ${ }^{f 1}$ indicates "complete dissatisfaction" and 7 indicates "complete statisfaction". EQ-5D-3L, EuroQoL five-dimension, three-level questionnaire; EQ-5D-5L, EuroQoL five-dimension, five-level questionnaire; EQ-VAS, EuroQoL visual analog scale; PedsQL-FIM, Pediatric Quality of Life Inventory - Family Impact Module (v2); QOLLTI-F, Quality of Life During Serious IIIness - Family Caregivers. SD, standard deviation. 

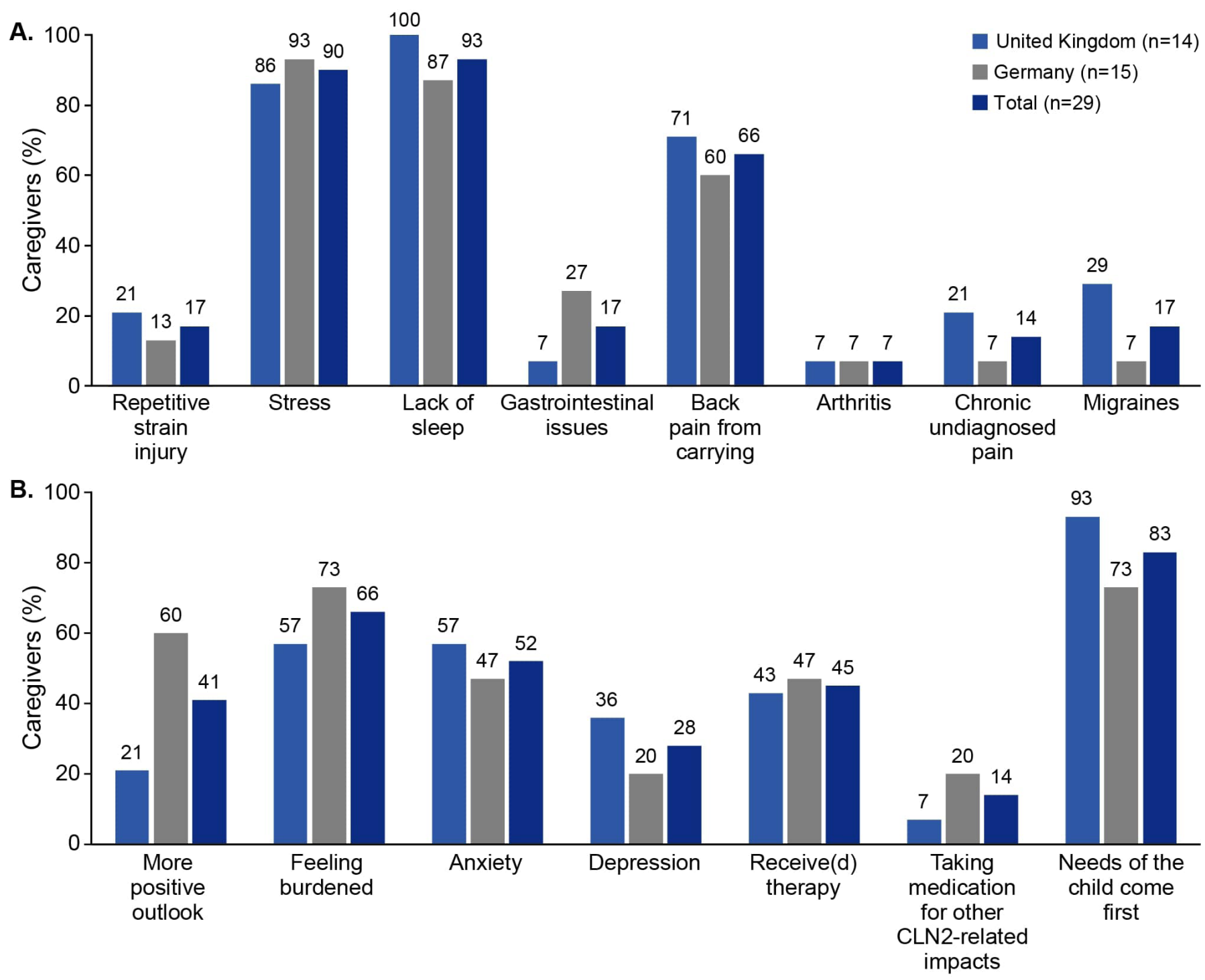

Figure 2. Impact of caring for a child with CLN2 disease on the (A) physical health (excludes adult siblings) and (B) emotional health of the caregivers (excludes adult siblings). CLN2, neuronal ceroid lipofuscinosis type 2.

Table 7. Health and wellbeing outcomes for caregivers compared with norms (excludes adult siblings)

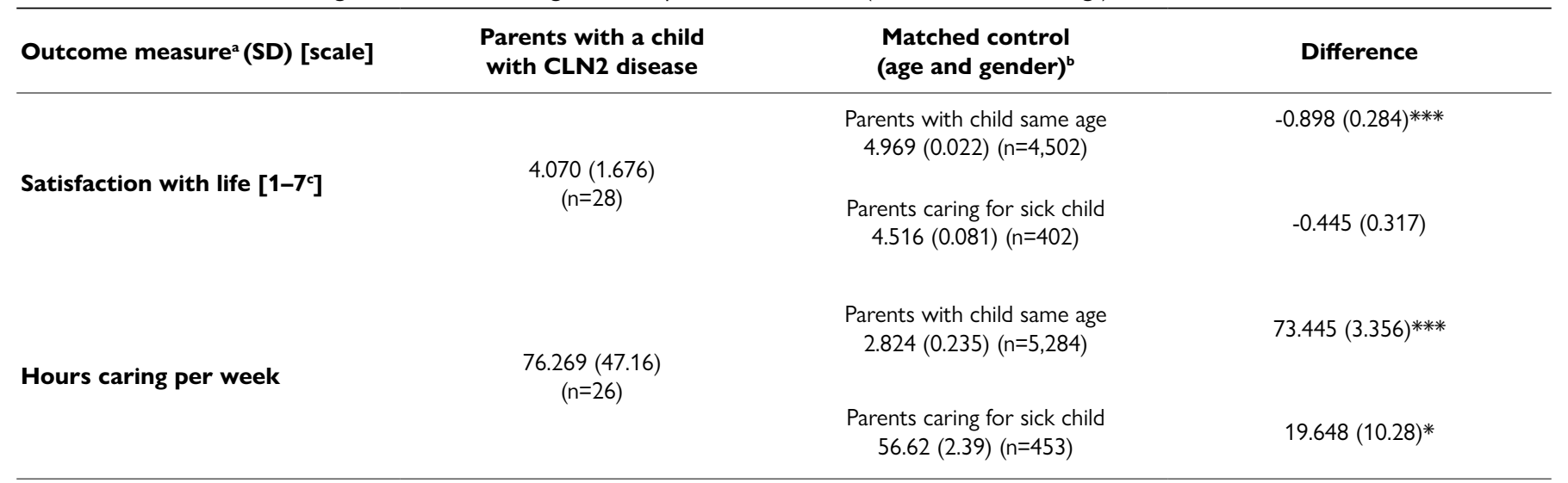


Table 7. Cont.

\begin{tabular}{|c|c|c|c|}
\hline Outcome measure $^{a}(\mathrm{SD})$ [scale] & $\begin{array}{l}\text { Parents with a child } \\
\text { with CLN2 disease }\end{array}$ & $\begin{array}{l}\text { Matched control } \\
\text { (age and gender) }^{\mathrm{b}}\end{array}$ & Difference \\
\hline & & $\begin{array}{l}\text { Parents with child same age } \\
6.696(0.019) \quad(n=4,917)\end{array}$ & $-1.321(0.246)^{* * *}$ \\
\hline \multirow[t]{3}{*}{ Hours sleeping per night } & $5.375(1.229)(n=28)$ & & \\
\hline & & $\begin{array}{l}\text { Parents caring for sick child } \\
6.207(0.066)(n=455)\end{array}$ & $-0.831(0.275)^{* * * *}$ \\
\hline & & $\begin{array}{l}\text { Parents with child same age } \\
4.676(0.022)(n=3,877)\end{array}$ & $-0.628(0.303)^{* *}$ \\
\hline \multirow[t]{3}{*}{ Happiness with partner [1-7] } & $4.048(1.244)(n=21)$ & & \\
\hline & & $\begin{array}{l}\text { Parents caring for sick child } \\
4.566(0.075)(n=360)\end{array}$ & $-0.518(0.320)$ \\
\hline & & $\begin{array}{l}\text { Parents with child same age } \\
2.401(0.015)(n=4,940)\end{array}$ & $-0.293(0.194)$ \\
\hline \multirow[t]{2}{*}{ Managing financially $\left[1-5^{d}\right]$} & $2.107(1.066)(n=28)$ & & \\
\hline & & $\begin{array}{l}\text { Parents caring for sick child } \\
2.677(0.052)(n=457)\end{array}$ & $-0.570(0.215)^{* * *}$ \\
\hline
\end{tabular}

Norms: data from Understanding Society [24] (UK and German data combined). ${ }^{\text {AAll }}$ treated as continuous; 'Understanding Society wave 4 (2012-13) (except 'Happiness with partner' taken from wave 3); "1 indicates "complete dissatisfaction" and 7 indicates "complete satisfaction"; $\mathrm{d} 1$ indicates comfortable and 5 indicates very difficult. ${ }^{*} \mathrm{p}<0.10$, ${ }^{*} \mathrm{*} p<0.05$, ${ }^{*}{ }^{*} \mathrm{p}<0.01 \mathrm{CLN} 2$, neuronal ceroid lipofuscinosis type 2; SD, standard deviation; UK, United Kingdom.
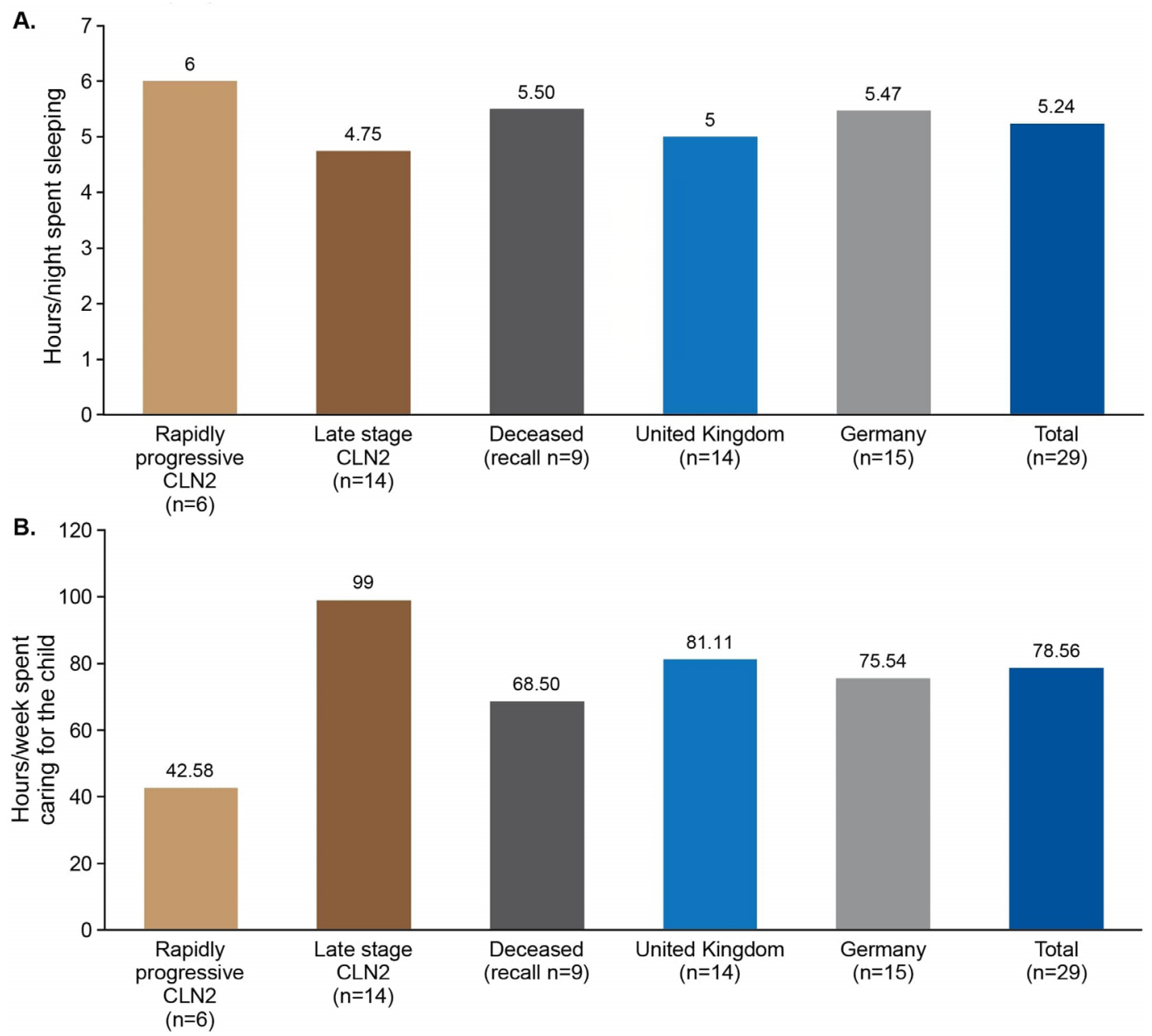

Figure 3. Impact of caring for a child with CLN2 disease on hours spent (A) sleeping (excludes adult siblings) and (B) caring for the child (excludes adult siblings). CLN2, neuronal ceroid lipofuscinosis type 2. 
Table 8. Percentage of caregivers of child with CLN2 disease reporting impact by various factors (excludes adult siblings)

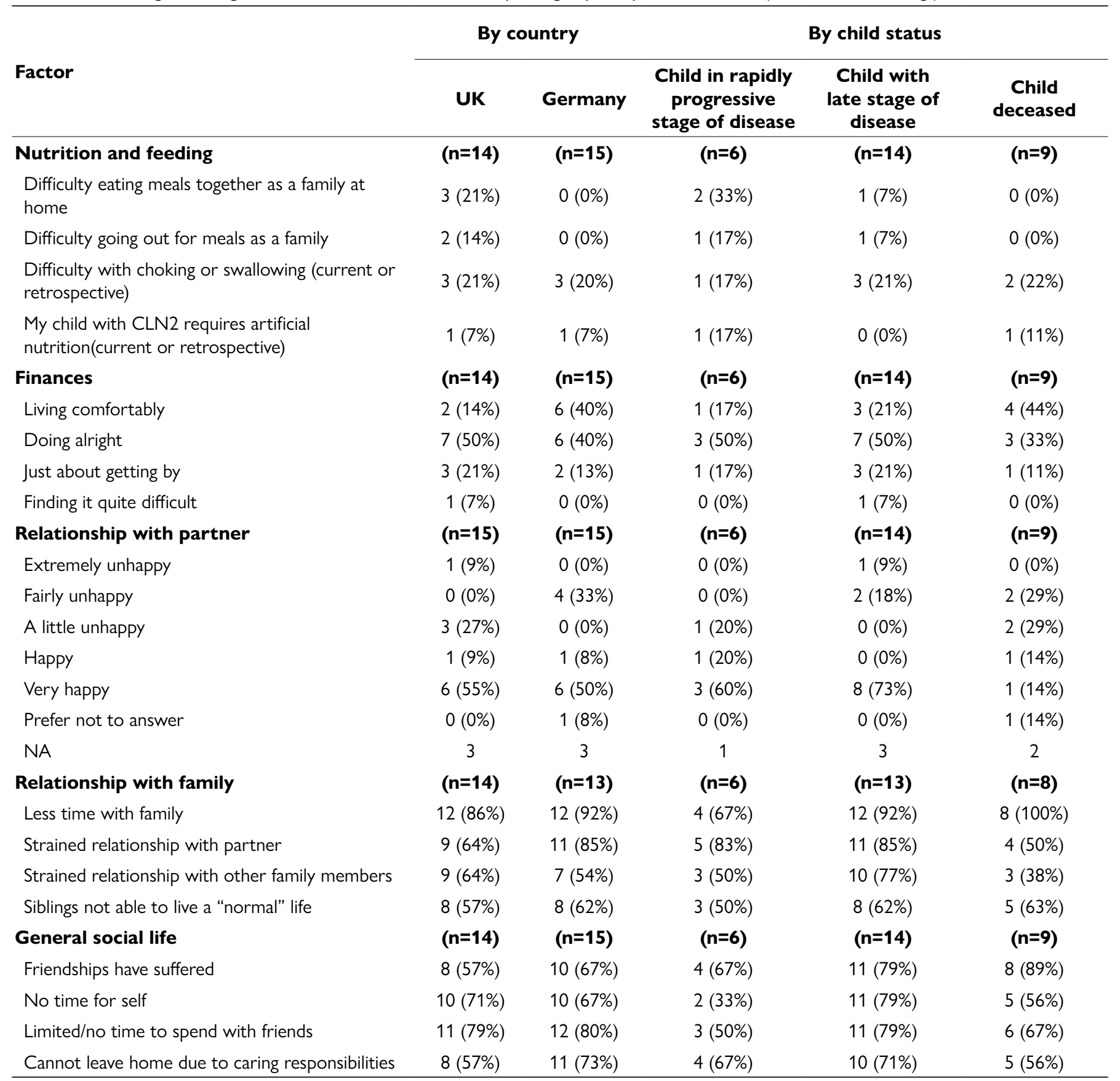

CLN2, neuronal ceroid lipofuscinosis type 2; NA, not applicable; UK, United Kingdom

(C23). However, other caregivers felt the quality and level of support differed between services, and ranged from "pretty good" (UK5.2) to "really poor" (physiotherapist).

The speed of relevant support is critical due to the rapidly progressive nature of this disease. Several caregivers felt that their current services needed to be quicker and more proactive with support as, "by the time we got one piece of equipment, it's almost like we don't need it anymore because he would have regressed so much"(C29). A few caregivers felt that some services needed the option of being accelerated when a specific need arose. UK participants reported they received very limited training regarding the use of the gastrostomy feeding tube (see Supplementary Material file 4).

In Germany, the majority of caregivers mentioned that there is appropriate support available for their child, but accessing appropriate support required a lot of knowledge about which services they were eligible for, how to go about obtaining different support options, and a great deal of persistence. 


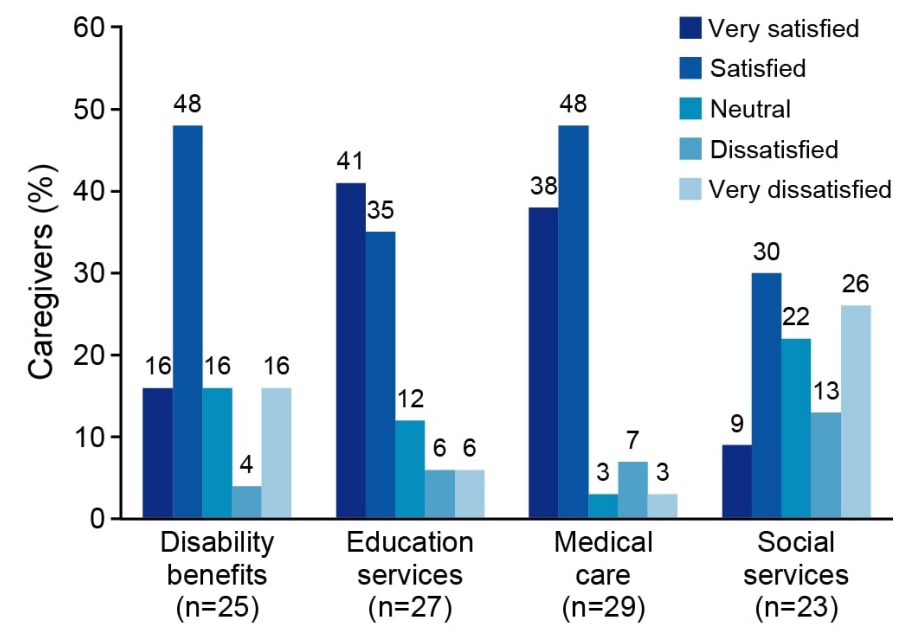

Figure 4. Caregiver satisfaction with support received by child (excludes adult siblings).

Many caregivers similarly talked about such difficulties when trying to access special needs schools (see Supplementary Material file 4).

Caregiving activities were often extensive and constant, revolving around any schooling, and medical management; they continued through the night, attending to symptoms, and even with some sleep there were often early starts to the day when the child awoke and then late evening activities in preparing food for the next day. One caregiver described their child as like " $a$ sick infant, it [the situation] is always acute" (C02).

\section{Support for Caregivers}

Caregivers reported significantly lower life satisfaction compared with parents of a child of the same age (see Table 7 and Supplementary Material file 4) and described impacts on social and family relationships (see Table 8 and Supplementary Material file 4). They were asked to rate their satisfaction with the level of support given to them from specified sources and responses were very variable. Most were 'very satisfied' or 'satisfied' with the support from partners $(72 \%)$ or other family members (66\%). There was greater spread across levels of satisfaction of support from friends (52\%) and government (31\%), and satisfaction or neutral about psychologists or counselors (both 28\%). Caregivers were mostly 'very satisfied' or 'satisfied' with support at school (62\%), but less so with support at work (41\%). There was general satisfaction with the support given to them from HCPs (76\%), advocate groups (45\%) and palliative care (48\%); neutral or dissatisfaction was expressed regarding the level of support from faith groups (14\%).

However, many caregivers found it difficult to admit they needed help and were reluctant to hand over caring responsibilities. Participants also highlighted the need for further support, including practical support for caring, information and advice on how to manage the process of receiving appropriate support from government and health insurance bodies, as well as counseling of emotional and physical health needs.

\section{Happiness With Their Partner}

Compared to parents with a child of the same age, caregivers of a child with CLN2 disease (both UK and German combined) reported significantly lower happiness with their partner $(-0.6$ on a 1 to 7 scale; Table 7).

The 23 caregivers who were in a relationship with a partner were asked how caring for a child with CLN2 disease impacted this relationship. In rating their degree of happiness in their relationship, about half of the participants $(n=12 ; 52 \%)$ were 'very happy', all of whom were current caregivers. Most bereaved caregivers were 'a little unhappy' (UK) or 'fairly unhappy' (Germany) in their relationship ( $\mathrm{n}=4 / 7 ; 57 \%)$ (Table 8). A number of caregivers mentioned difficulties within their relationships with their partners $(n=8 ; 35 \%)$. Two caregivers reported preexisting problems within their relationships being made worse as a result of the caregiving demands, which ultimately led to separation. Two caregivers specifically discussed their spouses' mental health difficulties which contributed to their caregiver burden and ultimately led to divorce. Another caregiver got divorced because they felt left alone with the burden of care while their partner was working.

\section{Financial Management}

Most caregivers reported managing financially, with half in the UK 'doing alright' $(\mathrm{n}=7 / 14 ; 50 \%)$, whereas those in Germany were split between 'living comfortably' and 'doing alright' $(\mathrm{n}=12 / 15$; 80\%) (Table 8). For most German participants, buying and moving to a more accessible property was not relevant ( $93 \%$ and $80 \%$, respectively). However, this was more relevant to the UK sample, where $36 \%$ bought a more accessible property and $50 \%$ moved to a more accessible property, both of which were self- or family-funded. Only one had government funding for cost of moving. Families mainly self-funded structural adaptations in the home (particularly in Germany) and adaptations to their family car (particularly in Germany). In the UK, caregivers reported that the need to self-fund was partly due to the National Health Service (NHS) not covering some equipment that the caregiver considered necessary, and partly due to the NHS not supplying the equipment or required funding in a timely manner, as their child's condition progressed. The government mainly funded equipment for the home, feeding equipment, and a wheelchair (particularly in Germany). Any cost for overnight accommodation during hospitalizations of their child was mainly self- or family-funded in the UK (50\%), and government funded in Germany (29\%). 


\section{Work Productivity and Activity Impairment}

The UK and German participants reported differences in the impact of caring for a child or children with CLN2 disease on their employment status (Table 9). In the UK, primary caregivers generally gave up work completely, whereas in Germany employers were mostly understanding and flexible. More primary caregivers in Germany were in full- or part-time employment $(n=7 / 10 ; 70 \%)$ than UK primary caregivers $(n=3 / 9$; $33 \%$ ), while an equal number of secondary caregivers were employed in the UK and Germany. Secondary caregivers were mostly employed full-time in both countries.

Four participants from Germany reported no impact on their work. For the other participants (both currently working and previously working), $67 \%$ in the UK and $45 \%$ in Germany reported taking annual/sick leave for caring responsibilities. The second highest impacts also differed between these countries, with $55 \%$ of participants from the UK turning down greater job responsibilities and $36 \%$ of those from Germany having restricted shifts/times to work. Secondary caregivers had greater impact on their work compared to primary caregivers in terms of absenteeism and presenteeism compared to primary caregivers.

Responses to the Work Productivity and Activity Impairment Questionnaire: Specific Health Problem (v2) (WPAI:SHP) questionnaire indicated that caring for a child with CLN2 disease had a greater impact on secondary caregivers' ability to work than primary caregivers (in terms of both absenteeism and presenteeism; Table 9). This was also the case for the percentage of overall (work and non-work) activity impairment for the UK. However, the small numbers of caregivers within work make it difficult to make any clear claims about the relative impact of work impairment between primary and secondary caregivers.

\section{Impact of Disease Stage on Caregiver Burden}

Disease stage (rapidly progressive, late, and deceased) had some impact on caregiver burden (Table 6). Caregivers of children in the late stage of the disease reported more impacts than those in the rapidly progressive stage and bereaved stages in relation to greater number of hours caring, less sleep, and lower QoL (by QOLLTI-F and by PedsQL-FIM, apart from the relationship domain). Overall happiness reduced with disease stage but life satisfaction was broadly similar across stages (Table 8).

In addition, QOLLTI-F and parent-related PedsQL-FIM scores were considerably lower in the late disease stage than the bereaved stage, with these assessments of QoL in the rapidly progressive stage falling between the two (Table 6). PedsQL-

Table 9. Work Productivity and Activity Impairment (WPAI) by caring role (including adult siblings)

\begin{tabular}{|c|c|c|c|c|c|c|c|}
\hline \multirow[t]{2}{*}{ Mean WPAI (SD) } & \multicolumn{3}{|c|}{ UK } & \multicolumn{2}{|c|}{ Germany } & \multicolumn{2}{|c|}{$\begin{array}{c}\text { Unmatched controls - EU } \\
\text { National Health and Wellness } \\
\text { Survey [45] }\end{array}$} \\
\hline & $\begin{array}{l}\text { Primary } \\
\text { caregiver }^{\mathbf{a}}\end{array}$ & $\begin{array}{l}\text { Secondary } \\
\text { caregiver }^{b}\end{array}$ & Sibling ${ }^{c}$ & $\begin{array}{l}\text { Primary } \\
\text { caregiver }^{\text {d }}\end{array}$ & $\begin{array}{l}\text { Secondary } \\
\text { caregiver }^{\mathrm{e}}\end{array}$ & $\begin{array}{l}\text { Caregiver of } \\
\text { cancer patient }\end{array}$ & $\begin{array}{c}\text { Non- } \\
\text { caregiver }\end{array}$ \\
\hline & $(n=2)$ & $(n=3)$ & $(n=1)$ & $(n=4)$ & $(n=5)$ & $(n=1,713)$ & $(n=103,868)$ \\
\hline \multirow{2}{*}{$\begin{array}{l}\text { Absenteeism: } \% \\
\text { worktime missed due } \\
\text { to challenge } \mathrm{f}^{\mathrm{f}}\end{array}$} & $0(0)$ & $8.33(14.43)$ & $0(\mathrm{NA})$ & $0(0)$ & $5.36(7.36)$ & $8.97(22.83)$ & $5.13(18.59)$ \\
\hline & $(n=1)$ & $(n=3)$ & $(n=1)$ & $(n=5)$ & $(n=5)$ & $(n=1,713)$ & $(n=103,868)$ \\
\hline $\begin{array}{l}\text { Presenteeism: } \% \\
\text { impairment to } \\
\text { productivity at work }\end{array}$ & $10(\mathrm{NA})$ & $23.33(40.41)$ & $0(\mathrm{NA})$ & $\begin{array}{c}22.50 \\
(38.62)\end{array}$ & $20(23.09)$ & $23.47(26.18)$ & $15.25(22.60)$ \\
\hline $\begin{array}{l}\% \text { total work } \\
\text { impairment (time \& } \\
\text { productivity) }\end{array}$ & $(n=9)$ & $(n=5)$ & $(n=2)$ & $(n=10)$ & $(n=5)$ & $(n=1,713)$ & $(n=103,868)$ \\
\hline $\begin{array}{l}\% \text { total activity } \\
\text { impairment }^{g}\end{array}$ & $56.67(28.28)$ & 76 (19.49) & $30(42.43)$ & 28 (39.94) & 18 (17.89) & $31.76(29.93)$ & $23.64(28.01)$ \\
\hline
\end{tabular}

Item-level $\mathrm{n}$ values refer to non-missing responses. Absenteeism defined as \% worktime missed due to challenge. Presenteeism defined as \% impairment to productivity at work. Total work impairment: sum of absenteeism and presenteeism. ${ }^{a}$ Of nine respondents, four working and five not working; ' ${ }^{\circ}$ f five respondents, three working and two not working; ' $O$ f two respondents, one working and one not working; ${ }^{\mathrm{D}} \mathrm{Of}$ ten respondents, five working and five not working; 'Five respondents, all working. ${ }^{f}$ Caregivers and adult siblings in current paid employment only; 'All caregivers and adult siblings. EU, European Union; NA, not applicable; SD, standard deviation; UK, United Kingdom; WPAI, Work Productivity and Activity Impairment Questionnalre 
FIM domain scores were lowest for families with a child in the late stage of CLN2 disease for all domains except relationships.

\section{Discussion}

This study explored the challenges that families face when living with and caring for a child or children affected by CLN2 disease. 19 families from Germany and the UK participated in the face-to-face survey. Participating families included those with surviving children who spanned stages of CLN2 disease, as well as families who had experienced bereavement. In particular, the majority of the German caregivers either had a child in the late stage of CLN2 disease or had been bereaved. In addition, the study provided the opportunity for siblings of those affected by the disease to take part (results largely not reported here).

The key findings from the study were: (i) caregivers and adult siblings had reduced HRQoL compared to age and gendermatched controls (UK: 0.78 vs. $0.89, p<0.01$; Germany: 0.87 vs. $0.95, p<0.05)$, as well as a range of physical and emotional impacts; (ii) significant reduction in sleep (5.4 vs. 6.7 hours, $p<0.01$ ); (iii) increased hours of caregiving (76.3 vs. 2.8 hours, $p<0.01$ ); (iv) significantly lower life satisfaction (4.1 vs. $5.0, p<0.01$ ) and lower happiness with their partner (4.0 vs. $4.7, p<0.05)$; (v) significant burden on finances ( 2.1 vs. $2.4 p<0.01$ ) due to home adaptations and loss of income; and (vi) that late stage of disease had more impacts on caregivers than for those whose child was in the rapidly progressive stage or who were bereaved. Results from this study align with aspects from the wider literature. For instance, caregivers looking after a family member with a life-limiting condition have support needs of their own and experience considerable psychological effects as a result of their role [31]. When a life-threatening illness is diagnosed and treated, families caring for the individual become involved in the many facets of caring for the individual along the trajectory of the disease [46]. Caregiving is a normal part of being the parent of a young child, but this role is considerably altered when a child experiences a life-threatening disease, with functional limitations and increasing dependence on their caregiver [47].

A number of key themes from this study are also reported elsewhere. For instance, a UK-wide survey that investigated the experiences of 600 families affected by rare conditions similarly reported that families faced problems which included delayed diagnosis, misdiagnosis, practitioners' limited knowledge about the management of their child's condition, and the difficulties of accessing all the services required to care for children with the condition [48]. Other studies have also found that caregivers experienced frustrations with professional support [31].

In common with the outcomes found in this study, caregiving for individuals with life-limiting conditions may have a negative impact on many dimensions of the caregiver's life, including physical and emotional health, and family and social relationships $[31,49,50]$. HRQoL scores reported in this study were lower for caregivers of children with CLN2 disease than for age/gender population norms but were similar to those reported in adults diagnosed with gout, chronic ischemic heart disease, epilepsy, or diabetes [51].

There were some limitations with this study, with many being related to the inherent challenges of conducting research in an ultra-orphan disease and the very small numbers of participants eligible for inclusion in the study. Although the families of affected children at different stages of CLN2 disease were invited, the German sample consisted exclusively of late stage and bereaved caregivers. It is not known if those that declined or did not respond had a child who would have been categorized in the earlier stages of CLN2 disease. Although caregivers of children in the earlier stages of disease were missing from the sample, some of the retrospective accounts provided indicate the daily difficulties around schooling and purchasing equipment, with which such caregivers have to contend. The lack of patients in this group may also reflect the exclusion criteria (i.e. not participating in a clinical trial). Consequently, the impact of CLN2 disease on caregivers of newly-diagnosed children has not been explored in detail, other than by retrospective accounts from caregivers of children with more advanced stage disease. Analysis of the quantitative data is limited due to the small sample size; it was not possible to control for potentially relevant characteristics (such as disease stage) when making comparisons between the UK and Germany. Some of the quantitative data combined current caregivers with bereaved caregivers, which relied upon accurate recall. The child abilities and disease stage score relied upon the caregiver rating, which was based on a study-specific adaptation of the Hamburg LINCL Scale. This version has not been validated for use, although caregivers did not report any problems with completing the questions.

Ethical considerations are also an important factor when conducting studies of this nature. Surveys describing family experiences of a disease can be burdensome for participants, both with respect to the time required to complete the questionnaire and with the emotional upheaval of recalling experiences and accounts of the disease; this is especially the case for bereaved families [52]. Accordingly, when designing this study, an emphasis was placed on minimising the time required by participating families, ensuring that study materials were worded in a sensitive manner and by using sensitive and experienced interviewers.

In addition, without the clinician-completed Hamburg LINCL Scale, there was no way to assess the accuracy of parental reporting of disease stage. Although, there were similarities between family impacts in both the UK and Germany, the rarity of CLN2 disease and small sample size in the present study makes generalization across Europe difficult, where family needs and challenges in other countries may differ. Replication of the study presented here across a broader geographic and cultural range may support a longer-term need for comprehensive and meaningful guidance for those families dealing with a diagnosis of CLN2 disease. 


\section{Conclusion}

Families caring for a child affected by CLN2 disease must cope with many difficult emotional, physical, professional, financial, and organizational challenges. Following diagnosis of a lifelimiting condition in their child, caregivers have to contend with impacts on their sleep, physical and emotional health, and family and social relationships. In addition, when caregivers gave up employment or reduced work hours, this had a financial impact that was compounded by the need to pay for care equipment and home adaptations. Despite the many difficulties, caregivers reported that they simply needed to accept the situation as it was and deal with it for the sake of their children.

\section{Acknowledgements}

The authors are very grateful to the study participants and appreciate the time spent with the researchers during the course of this study. We would also like to thank the fantastic recruitment and general study support provided by the Batten Disease Family Association, NCL-Gruppe Deutschland e.V., and Klinik und Poliklinik für Kinder- und Jugendmedizin, Universitätsklinikum Hamburg-Eppendorf. We would also like to acknowledge the wonderful study support by Thomas Finger (Quali-Team, Germany) and Chloe Patel, Samuel Llewellyn and Hayley de Frietas (ICON at the time of the study); and the editorial assistance of Monique Curran in preparing the manuscript.

Understanding Society is an initiative by the Economic and Social Research Council, with scientific leadership by the Institute for Social and Economic Research, University of Essex, and survey delivery by the National Centre for Social Research and TNS BRMB.

\section{Funding}

This study was funded by BioMarin Pharmaceutical Inc.

\section{Ethics Approval and Consent to Participate}

The study protocol and materials were reviewed and approved by an Institutional Review Board (Salus IRB, protocol numbers 0439-0037 and 0439-0037-Phase 2) and by a local board in Germany (Ethik-Kommission der Ärztekammer Hamburg, study reference PV5057).

\section{Authors' Contributions}

$\mathrm{TB}, \mathrm{RB}, \mathrm{LE}$ and JM led the development and finalization of the study protocol and survey materials, with support in selection of quantitative measures by $\mathrm{TP}$, significant input by $\mathrm{AO}$, and oversight by MJ. RB and LE conducted family surveys in the UK and trained the researchers in Germany; with project leadership and data collection in Germany by IA-TS. TB, RB, LE and
JM led on the analysis and report writing, with significant contributions for the German qualitative data analysis by IA-TS and all quantitative data by TP. AS, ID and AW provided review of the study protocol, survey materials, and invited families to the study. All authors reviewed and approved the final manuscript.

\section{Declaration of Conflicting Interests}

Rachel Ballinger, Lina Eliasson and Jake Macey as employees of ICON were funded to conduct the study by BioMarin Pharmaceutical Inc. Study funds were used to cover the fees of Tessa Peasgood and Irini-Alexia Terzakis-Snyder. Tessa Peasgood, Iris Dyck and Irini-Alexia Terzakis-Snyder declare that they have no competing interests. Batten Disease Family Association have received collaborative funds from BioMarin Pharmaceutical Inc. for providing support to this study. Angela Schulz has previously conducted clinical trials on behalf of BioMarin Pharmaceutical Inc. Mohit Jain and Andrew Olaye are employees of BioMarin Europe, as was Thomas Butt at the time of the study. Lina Eliasson and Jake Macey were employees of ICON at the time of the study. Editorial support was provided by Costello Medical.

\section{Data Sharing Statement}

The data that support the findings of this study are available from ICON plc but restrictions apply to the availability of these data, which were used under license for the current study, and so are not publicly available. Data are however available from the authors upon reasonable request and with permission of BioMarin.

\section{Supplementary Material}

The following online material is available for this article: Supplementary file 1: Adult Sibling Survey. Supplementary file 2: Caregiver Survey. Supplementary file 3: Child Sibling Survey. Supplementary file 4: Supplementary Results.

\section{References}

1. Williams RE, Mole SE. New nomenclature and classification scheme for the neuronal ceroid lipofuscinoses. Neurology. 2012;79(2):183-191. doi: 10.1212/WNL.0b013e31825f0547

2. Anderson GW, Goebel HH, Simonati A. Human pathology in NCL. Biochim Biophys Acta. 2013;1832(11):1807-1826. doi: 10.1016/j.bbadis.2012.11.014

3. Haltia M, Goebel HH. The neuronal ceroid-lipofuscinoses: a historical introduction. Biochim Biophys Acta. 2013;1832(11):1795-1800. doi: 10.1016/j.bbadis.2012.08.012

4. Schulz A, Kohlschutter A, Mink J, Simonati A, Williams R. NCL diseases - clinical perspectives. Biochim Biophys Acta. 2013;1832(11):1801-1806. doi: 10.1016/j.bbadis.2013.04.008 
5. Mole S, Williams R. Neuronal ceroid-lipofuscinosis. GeneReviews ${ }^{\oplus}$. 2001. http://www.ncbi.nlm.nih.gov/books/ NBK1428/. Accessed October 09, 2016.

6. Mole SE, Williams RE. Neuronal ceroid-lipofuscinoses. In: Pagon RA, Adam MP, Ardinger HH, et al., eds. GeneReviews ${ }^{\circledR}$. University of Washington; 1993-2016. 2001 Oct 10 [updated 2013 Aug 1].

7. Nickel M, Simonati A, Jacoby D, et al. Disease characteristics and progression in patients with late-infantile neuronal ceroid lipofuscinosis type 2 (CLN2) disease: an observational cohort study. Lancet Child Adolesc Health. 2018;2(8):582-590. doi: 10.1016/S2352-4642(18)30179-2

8. Williams RE. Appendix 1: NCL incidence and prevalence data. In: Mole SE, Williams RE, Goebels HH, eds. The neuronal ceroid lipofuscinoses (Batten disease). 2nd ed. Oxford: Oxford University Press; 2011:361-365. doi: $10.1093 / \mathrm{med} / 9780199590018.003 .0023$

9. Chang JDM, Cooper BL, Davidson B, et al. CLN2. In: Mole S, Williams R, Goebel H, eds. The neuronal ceroid lipofuscinoses (Batten disease). Oxford University Press; 2011:80-109. doi: 10.1093/med/9780199590018.003.0007

10. Moore SJ, Buckley DJ, MacMillan A, et al. The clinical and genetic epidemiology of neuronal ceroid lipofuscinosis in Newfoundland. Clin Genet. 2008;74(3):213-222. doi: 10.1111/j.1399-0004.2008.01054.x

11. Batten Disease Family Association. CLN2 disease, lateinfantile. http://www.bdfa-uk.org.uk/cln2-disease-lateinfantile. Accessed August 05, 2016.

12. Santorelli FM, Garavaglia B, Cardona F, et al. Molecular epidemiology of childhood neuronal ceroid-lipofuscinosis in Italy. Orphanet J Rare Dis. 2013;8(1):19. doi: 10.1186/1750-1172-8-19

13. Schulz A, Ajayi T, Specchio N, et al. Study of intraventricular cerliponase alfa for CLN2 disease. $N$ Engl J Med. 2018;378(20):1898-1907. doi: 10.1056/NEJMoa1712649

14. Food and Drug Administration. Brineura (cerliponase alfa) Injection. https://www.accessdata.fda.gov/drugsatfda_docs/ nda/2017/761052orig1s000toc.cfm Accessed April 18, 2018.

15. European Medicines Agency. Summary of Product Characteristics. http://www.ema.europa.eu/docs/en_ gb/document_library/epar_-_product_information/ human/004065/wc500229798.pdf. accessed april 18, 2018.

16. Souweidane MM, Fraser JF, Arkin LM, et al. Gene therapy for late infantile neuronal ceroid lipofuscinosis: neurosurgical considerations. J Neurosurg Pediatr. 2010;6(2):115-122. doi: 10.3171/2010.4.PEDS09507

17. Dolisca SB, Mehta M, Pearce DA, Mink JW, Maria BL. Batten disease: clinical aspects, molecular mechanisms, translational science, and future directions. J Child Neurol. 2013;28(9):1074-1100. doi: 10.1177/0883073813493665
18. Neverman NJ, Best HL, Hofmann SL, Hughes SM. Experimental therapies in the neuronal ceroid lipofuscinoses. Biochim Biophys Acta. 2015;1852(10):22922300. doi: 10.1016/j.bbadis.2015.04.026

19. Geraets RD, Koh S, Hastings ML, Kielian T, Pearce DA, Weimer JM. Moving towards effective therapeutic strategies for neuronal ceroid lipofuscinosis. Orphanet J Rare Dis. 2016;11(1):40. doi: 10.1186/s13023-016-0414-2

20. Steele R, Davies B. Impact on parents when a child has a progressive, life-threatening illness. Int J Palliat Nurs. 2006;12(12):576-585. doi: 10.12968/ijpn.2006.12.12.22544

21. Malcolm C, Adams S, Anderson G, et al. The symptom profile and experience of children with rare life-limiting conditions: perspectives of their families and key health professionals. Cancer Care Research Centre, University of Stirling, 2011. https://www.gosh.nhs.uk/file/474/download. Accessed May,24 2018.

22. Pelentsov LJ, Laws TA, Esterman AJ. The supportive care needs of parents caring for a child with a rare disease: a scoping review. Disabil Health J. 2015;8(4):475-491. doi: 10.1016/j.dhjo.2015.03.009

23. Hinds PS, Kelly KP. Helping parents make and survive end of life decisions for their seriously ill child. Nurs Clin North Am. 2010;45(3):465-474. doi: 10.1016/j.cnur.2010.03.006

24. Thompson RJ Jr, Zeman JL, Fanurik D, Sirotkin-Roses $\mathrm{M}$. The role of parent stress and coping and family functioning in parent and child adjustment to Duchenne muscular dystrophy. J Clin Psychol. 1992;48(1):11-19. doi: 10.1002/1097-4679(199201)48:13.0.CO;2-4

25. Blum RW, Resnick MD, Nelson R, St Germaine A. Family and peer issues among adolescents with spina bifida and cerebral palsy. Pediatrics. 1991;88:280-285.

26. Ulus Y, Tander B, Akyol Y, et al. Functional disability of children with spina bifida: its impact on parents' psychological status and family functioning. Dev Neurorehabil. 2012;15(5):322-328. doi: 10.3109/17518423.2012.691119

27. Rofail D, Maguire L, Kissner M, Colligs A, Abetz-Webb L. A review of the social, psychological, and economic burdens experienced by people with spina bifida and their caregivers. Neurol Ther. 2013;2(1-2):1-12. doi: 10.1007/ s40120-013-0007-0

28. Case-Smith J. Parenting a child with a chronic medical condition. Am J Occup Ther. 2004;58(5):551-560. doi: 10.5014/ajot.58.5.551

29. Dellve L, Samuelsson L, Tallborn A, Fasth A, Hallberg LR. Stress and well-being among parents of children with rare diseases: a prospective intervention study. J Adv Nurs. 2006;53(4):392-402. doi: 10.1111/j.1365-2648.2006.03736.x

30. Adams HR, Rose K, Augustine EF, et al. Experience, knowledge, and opinions about childhood genetic testing 
in Batten disease. Mol Genet Metab. 2014;111(2):197-202. doi: 10.1016/j.ymgme.2013.10.017

31. Rodriguez A, King N. The lived experience of parenting a child with a life-limiting condition: a focus on the mental health realm. Palliat Support Care. 2009;7(1):7-12. doi: $10.1017 /$ S1478951509000030

32. Scrambler S, Williams R. Batten Disease Family Support Project: The Support Needs of Families of Children with Batten Disease: An Audit of the Efficacy of Existing Services and an In-depth Study of Families Needs. Unpublished report for Batten Disease Family Association. 2008.

33. Knies G, Lynn, P. eds. Understanding Society: UK Household Longitudinal Study: Wave 1-5, 2009-2014. Institute for Social and Economic Research University of Essex; 2015.

34. Reilly MC, Zbrozek AS, Dukes EM. The validity and reproducibility of a work productivity and activity impairment instrument. Pharmacoeconomics. 1993;4(5):353-365. doi: 10.2165/00019053-19930405000006

35. Herdman M, Gudex C, Lloyd A, et al. Development and preliminary testing of the new five-level version of EQ-5D (EQ-5D-5L). Qual Life Res. 2011;20(10):1727-1736. doi: 10.1007/s11136-011-9903-x

36. Szende A, Janssen J, Cabases J. Self-reported population health: an international perspective based on EQ-5D. 7th ed. Springer Open; 2014. doi: 10.1007/978-94-007-7596-1

37. Cohen R, Leis AM, Kuhl D, Charbonneau C, Ritvo P, Ashbury FD. QOLLTI-F: measuring family carer quality of life. Palliat Med. 2006;20(8):755-767. doi: 10.1177/0269216306072764

38. Varni JW, Sherman SA, Burwinkle TM, Dickinson PE, Dixon P. The PedsQL ${ }^{\mathrm{TM}}$ Family Impact Module: preliminary reliability and validity. Health Qual Life Outcomes. 2004;2(1):55. doi: 10.1186/1477-7525-2-55

39. Ravens-Sieberer U, Gosch A, Rajmil L, et al. KIDSCREEN-52 quality-of-life measure for children and adolescents. Expert Rev Pharmacoecon Outcomes Res. 2005;5(3):353-364. doi: 10.1586/14737167.5.3.353

40. Ravens-Sieberer U, Gosch A, Rajmil L, et al. The KIDSCREEN-52 quality of life measure for children and adolescents: psychometric results from a crosscultural survey in 13 European countries. Value Health. 2008;11(4):645-658. doi: 10.1111/j.1524-4733.2007.00291.x

41. European Social Survey. ESS Round 7 Source Questionnaire. London: ESS ERIC Headquarters, Centre for Comparative Social Surveys; 2014.
42. Chen G, Stevens K, Rowen D, Ratcliffe J. From KIDSCREEN-10 to CHU9D: creating a unique mapping algorithm for application in economic evaluation. Health Qual Life Outcomes. 2014;12(1):134. doi: 10.1186/s12955014-0134-Z

43. Steinfeld R, Heim P, von Gregory H, et al. Late infantile neuronal ceroid lipofuscinosis: quantitative description of the clinical course in patients with CLN2 mutations. Am J Med Genet. 2002;112(4):347-354. doi: 10.1002/ajmg.10660

44. Hendriksz CJ, Lavery C, Coker M, et al. The burden endured by caregivers of patients with Morquio A syndrome: results from an international patient-reported outcomes survey. J Inborn Errors Metab Screen. 2014;2:1-8. doi: $10.1177 / 2326409814540872$

45. Goren A, Gilloteau I, Lees M, DaCosta Dibonaventura M. Quantifying the burden of informal caregiving for patients with cancer in Europe. Support Care Cancer. 2014;22(6):1637-1646. doi: 10.1007/s00520-014-2122-6

46. Kim Y, Given BA. Quality of life of family caregivers of cancer survivors: across the trajectory of the illness. Cancer. 2008;112(S11):2556-2568. doi: 10.1002/cncr.23449

47. Raina P, O'Donnell M, Rosenbaum P, et al. The health and well-being of caregivers of children with cerebral palsy. Pediatrics. 2005;115(6):e626-e636. doi: 10.1542/ peds.2004-1689

48. Limb L, Nutt S, Sen A. Experiences of rare diseases: an insight from patients and families. London UK: Rare Disease UK. 2010. http://www.raredisease.org.uk/ourwork/experiences-of-rare-diseases-an-insight-frompatients-and-families-2010/. Accessed Aug 31, 2016.

49. Given BA, Given CW, Sherwood P. The challenge of quality cancer care for family caregivers. Semin Oncol Nurs. 2012;28(4):205-212. doi: 10.1016/j.soncn.2012.09.002

50. Jones BL. The challenge of quality care for family caregivers in pediatric cancer care. Semin Oncol Nurs. 2012;28(4):213220. doi: 10.1016/j.soncn.2012.09.003

51. Sullivan PW, Ghushchyan V. Preference-based EQ$5 \mathrm{D}$ index scores for chronic conditions in the United States. Med Decis Making. 2006;26(4):410-420. doi: 10.1177/0272989X06290495

52. Dyregrov K. Bereaved parents' experience of research participation. Soc Sci Med. 2004;58(2):391-400. doi: 10.1016/S0277-9536(03)00205-3 